\title{
Validation of two independent retrievals of SCIAMACHY water vapour columns using radiosonde data
}

\author{
A. du Piesanie ${ }^{1}$, A. J. M. Piters ${ }^{1}$, I. Aben ${ }^{2}$, H. Schrijver ${ }^{2}$, P. Wang ${ }^{1}$, and S. Noël ${ }^{3}$ \\ ${ }^{1}$ Royal Netherlands Meteorological Institute (KNMI), de Bilt, the Netherlands \\ ${ }^{2}$ Netherlands Institute for Space Research (SRON), Utrecht, the Netherlands \\ ${ }^{3}$ Institute of Environmental Physics, University of Bremen, Bremen, Germany
}

Correspondence to: A. J. M. Piters (ankie.piters@knmi.nl)

Received: 26 November 2012 - Published in Atmos. Meas. Tech. Discuss.: 21 January 2013

Revised: 19 August 2013 - Accepted: 6 September 2013 - Published: 31 October 2013

\begin{abstract}
Two independently derived SCIAMACHY total water vapour column (WVC) products are compared with integrated water vapour data calculated from radiosonde measurements, and with each other. The two SCIAMACHY WVC products are retrieved with two different retrieval algorithms applied in the visible and shortwave infrared wavelength regions respectively. The first SCIAMACHY WVC product used in the comparison is ESA's level 2 version 5.01 WVC product derived with the Air Mass Corrected Differential Optical Absorption Spectroscopy (AMC-DOAS) retrieval algorithm applied in the visible wavelength range (SCIAMACHY-ESA). The second SCIAMACHY WVC product is derived using the iterative maximum likelihood method (IMLM) in the short-wave infrared wavelength range and developed by Netherlands Institute for Space Research (SCIAMACHY-IMLM). Both SCIAMACHY WVC products are compared with collocated water vapour amounts determined from daily relative humidity radiosonde measurements obtained from the European Centre for Medium-Range Weather Forecasts (ECMWF) radiosonde network. The SCIAMACHY-ESA WVC product is compared with radiosonde-derived WVC amounts for an 18-month period from February 2010 to mid-August 2011, and the SCIAMACHY-IMLM WVC amounts are compared with radiosonde WVC amounts for the two individual years of 2004 and 2009. In addition the WVC amounts from SCIAMACHY-ESA and SCIAMACHY-IMLM are also compared with each other for a 1-month period for June 2009.
\end{abstract}

The AMC-DOAS method used to retrieve SCIAMACHYESA WVC is able to correct for water vapour present below the clouds and can be used during cloudy conditions over both land and ocean surfaces. Results indicate a good agreement between the WVC amounts of SCIAMACHY-ESA and that of radiosondes, with a mean difference of $-0.32 \mathrm{~g} \mathrm{~cm}^{-2}$ for all collocated cases. Overall the SCIAMACHY-ESA WVC amounts are smaller than the radiosonde WVC amounts, especially over oceans. For cloudy conditions the WVC bias has a clear dependence on the cloud top height and increases with increasing cloud top heights larger than approximately $2 \mathrm{~km}$. A likely cause for this could be the different vertical profile shapes of water vapour and $\mathrm{O}_{2}$ leading to different relative changes in their optical thickness, which makes the air mass factor (AMF) correction method used in the algorithm less suitable for high clouds. The SCIAMACHY-IMLM product's water vapour measurements are best used over land surfaces during cloudfree conditions, and in these cases a good agreement is found when compared to radiosonde WVC amounts, with a mean difference of $0.08 \mathrm{~g} \mathrm{~cm}^{-2}$. It is shown that over ocean surfaces during cloudy conditions the partial SCIAMACHYIMLM water vapour column above the cloud can be well estimated by using the simultaneously retrieved methane column to calculate the cloud top height. Comparing the two satellite WVC products with each other indicates that SCIAMACHYESA consistently measures higher WVC amounts than those of SCIAMACHY-IMLM. Furthermore, the importance of the choice of cloud product is highlighted, as intercomparisons between the two SCIAMACHY WVC products indicate that using different cloud products to screen water vapour data for cloud-free conditions influences the data selection and may ultimately lead to a variation in results. 
In the last section of the paper, various options for filtering the two SCIAMACHY WVC data sets are discussed and best selection criteria suggested.

\section{Introduction}

Water vapour is one of the most abundant constituents in the earth's atmosphere. It is the most important greenhouse gas because of its strong absorption of infrared radiation. The majority of water vapour is found in the lower parts of the atmosphere, and its distribution is highly variable. Water vapour has a key influence on weather (clouds, precipitation) and atmospheric chemistry (e.g. the $\mathrm{HO}_{\mathrm{x}}$ cycle). Accurate measurements of water vapour with good spatial and temporal coverage are essential to monitor the distribution and variability of water vapour, and thereby the effect on climate, weather and chemistry.

A variety of satellite remote sensing instruments are able to provide water vapour measurements on a global scale. Instruments able to retrieve water vapour from measurements in microwaves such as TOVS (Tiros Operational Vertical Sounder) and SSM/I (Spectral Sensor Microwave Imager) have the advantage that water vapour data are available for all cloud conditions during day and night on a global scale (Mieruch et al., 2010; Lang et al., 2007). A drawback of these measurements is that data are only available over the oceans and have low sensitivity for lower parts of the atmosphere (Schrijver et al., 2009). A similar shortfall is found with retrievals obtained from thermal infrared wavelength regions, as seen in measurements of the AIRS (Advanced Infrared Sounder) infrared spectrometer/radiometer, in combination with the AMSU (Advanced Microwave Sounding Unit) microwave instrument (Schrijver et al., 2009).

SCIAMACHY (Scanning and Imaging Absorption Spectrometer for Atmospheric Chartography), on board the European environmental satellite Envisat, uses atmospheric absorption spectra of high spectral resolution to derive vertical total water vapour column (WVC) amounts. In this study two independently derived SCIAMACHY total WVC products retrieved with two different retrieval algorithms applied in the visible and short-wave infrared wavelength regions respectively, and each with their own error characteristics, are compared to radiosondes and to each other. One of the advantages of SCIAMACHY retrieval results from the visible and short-wave infrared wavelength regions is that measurements are sensitive down to the boundary layer (Schrijver et al., 2009). This is particularly favourable for water vapour, since the majority of water vapour is found in the lower parts of the atmosphere. One disadvantage is that retrieval results can only be acquired during daylight side of the orbit, and furthermore the presence of clouds can obscure part of the retrieved column. The water vapour product retrieved from the visible wavelength region and used for this study makes use of a cloud correction method by applying an air mass correction factor (described in more detail in Sect. 2.2.1), and provides the possibility to retrieve meaningful water vapour columns during cloudy conditions. Measurement results obtained from the visible wavelength region are available over both land and ocean surfaces, whereas for the short-wave infrared region the low sensitivity over ocean surfaces caused by low reflectivity means that measurements from this wavelength range are limited to land surfaces only (Gloudemans et al., 2008) or to cloudy observations over the ocean (Gloudemans et al., 2009). However, in this wavelength window the sensitivity for the lower parts of the atmosphere is even stronger (Schrijver et al., 2009).

The SCIAMACHY product OL version 5.01, distributed by ESA, includes a total water vapour column retrieved with the AMC-DOAS (Air Mass Corrected Differential Optical Absorption Spectroscopy) method, applied to the visible wavelength region between 688 and $700 \mathrm{~nm}$. The AMC-DOAS retrieval algorithm, developed by the University of Bremen, was first used to derive water vapour column amounts from GOME (Global Ozone Monitoring Experiment) on board ERS-2 (Noël et al., 1999) and later SCIAMACHY (Noël et al., 2004, 2005) and GOME2 on MetOp (Noël et al., 2008). Mieruch et al. (2010) found a systematic difference between water vapour derived from GOME/SCIAMACHY with AMC-DOAS v1.0 and water vapour derived from SSM/I (Special Sensor Microwave/Imager) with the HOAPS (Hamburg Ocean Atmosphere Parameters and Fluxes from Satellite) v3.1 algorithm. This difference was on average $1-2 \mathrm{~kg} \mathrm{~m}^{-2}$ for clear-sky situations over ocean.

SCIAMACHY water vapour columns are also derived by the Netherlands Institute for Space Research (SRON) with the iterative maximum likelihood method (IMLM). This algorithm is applied to the short-wave infrared region and has been successfully used to retrieve $\mathrm{CO}$ (Gloudemans et al., 2008). More recently it has been used to retrieve $\mathrm{H}_{2} \mathrm{O}$ (Schrijver et al., 2009) using the spectral range between 2353 and $2368 \mathrm{~nm}$. Schrijver et al. (2009) compared the IMLM water vapour columns with European Centre for MediumRange Weather Forecasts (ECMWF) data and found an average difference of $0.1 \mathrm{~kg} \mathrm{~m}^{-2}$ for IMLM water vapour columns in clear-sky situations over land.

In this paper SCIAMACHY total WVC measurements are compared with integrated water vapour data obtained from collocated radiosonde measurements. A comparison with the total water vapour columns from the SCIAMACHY water vapour product retrieved by the AMC-DOAS method is performed for an 18-month period (February 2010 to mid-August 2011), and the comparison between the SCIAMACHY water vapour columns derived using the IMLM method is performed for a 2-year period for the years of 2004 and 2009. Furthermore, the two SCIAMACHY water vapour data sets are compared with each other and with radiosonde water vapour data for a 1-month period. 
In Sect. 2 the water vapour column data sets used are described in more detail. The comparisons between the radiosonde-derived water vapour columns and the two SCIAMACHY water vapour column products are performed in Sect. 3 and Sect. 4. In Sect. 5 both SCIAMACHY data sets are compared to each other, and in Sect. 6 the results and best selection criteria for the SCIAMACHY water vapour column products are discussed, together with the conclusions.

\section{Data sources}

\subsection{Radiosondes}

The two individual SCIAMACHY water vapour data sets are compared with integrated water vapour derived from radiosonde relative humidity measurements. The radiosonde measurement data used here were acquired from the European Centre for Medium-Range Weather Forecasts (ECMWF) radiosonde network (data obtained from ECMWF's Ecgate server https://ecaccess.ecmwf.int, registered users only). This network consists of daily radiosonde measurements from a large number of globally distributed ground measurement sites (Fig. 1). The number of globally performed radiosonde measurements available on a daily basis varies, and not all measurement sites necessarily perform a radiosonde measurement every day. Alternatively, some sites perform more than one measurement per day for example during measurement campaigns. In general balloonborne radiosondes are launched twice daily at 12:00 UTC and 00:00 UTC, and depending on the size of the balloon they can reach altitudes up to $30 \mathrm{~km}$. These global radiosonde humidity measurements are collected by various sonde types with different sensor characteristics. A number of methods have been developed to correct for biases in humidity observations. However many of these methods focus primarily on individual radiosonde instruments (Wang and Zhang, 2008). Overall the majority of radiosonde instrument types show a dry bias, predominantly in the upper troposphere where the bias can reach $5 \%$ to $8 \%$ in relative humidity (Sun et al., 2010). Each relative humidity profile obtained from the radiosonde measurements is integrated to a vertical column amount, provided the profile has enough measurement layers. The integration is performed using the pressure and specific humidity at each level in the vertical. Specific humidity is calculated using the relative humidity, pressure and saturated vapour pressure, which in turn is calculated according to the Goff-Gratch equation (Goff and Gratch, 1946).

\subsection{SCIAMACHY water vapour columns}

The SCIAMACHY instrument on board the European Space Agency's (ESA) Envisat satellite was launched in 2002 and stopped operations in April 2012. SCIAMACHY measures earthshine radiance and solar irradiance spectra from the ultraviolet, visible and near-infrared wavelength

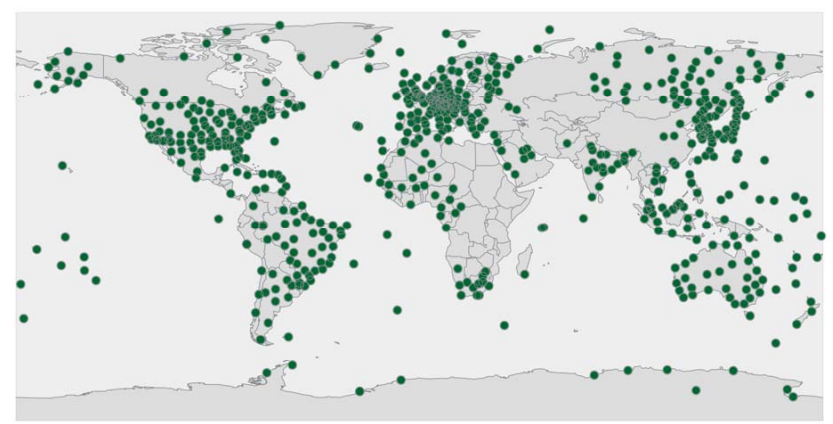

Fig. 1. Locations of the radiosonde stations used in both the SCIAMACHY-ESA and SCIAMACHY-IMLM water vapour column intercomparisons with radiosonde WVC data.

region (240-2380 nm) in limb and nadir viewing geometry (Bovensmann et al., 1999, Gottwald and Bovensmann, 2011). Envisat is operated in a sun-synchronous orbit and has an Equator crossing time of 10:00 local time. Individual ground pixel size depends on the selected integration time (Gottwald and Bovensmann, 2011). In the wavelength range between 2353 to $2368 \mathrm{~nm}$ where the IMLM is applied to derive the total WVC, a SCIAMACHY ground pixel typically has a spatial resolution of $120 \mathrm{~km} \times 30 \mathrm{~km}$ (Schrijver et al., 2009). In the shorter wavelength range where the AMCDOAS method is applied, a ground pixel has a typical size of $60 \mathrm{~km} \times 30 \mathrm{~km}$ (Noël et al., 2004).

\subsubsection{ESA product, version 5.01, AMC-DOAS method}

Total WVC amounts in the current SCIAMACHY level 2 version 5.01 ESA product are derived with the AMC-DOAS retrieval algorithm version 1.0 as developed by Noël et al. (2004). The AMC-DOAS method is a modified approach of the differential optical absorption spectroscopy (DOAS) method, using the differential absorption structures to derive total columns. The method is applied in a spectral fitting window between 688 and $700 \mathrm{~nm}$. Both $\mathrm{O}_{2}$ and water vapour absorb in this spectral region and have similar optical depths. The method is described by the following equation:

$\ln \left(\frac{I}{I_{0}}\right)=P-a\left(\tau_{\mathrm{O}_{2}}+c C_{\mathrm{v}}^{b}\right)$,

where $I$ and $I_{0}$ represent the measured earthshine radiance and irradiance spectra respectively, $\tau_{\mathrm{O}_{2}}$ represents the $\mathrm{O}_{2}$ optical depth, $C_{\mathrm{v}}$ denotes the vertical water vapour column, $c$ is the water vapour air mass factor, $b$ is a parameter correcting for saturation effects in the water vapour absorption lines, and the scalar factor $a$ represents the so-called air mass factor correction factor (AMF CF). All spectral broadband contributions resulting from Rayleigh and Mie scattering or surface albedo are approximated by a polynomial $P$. The parameters $b, c$, and $\tau_{\mathrm{O}_{2}}$ are calculated from radiative transfer calculations, and $P, a$, and $C_{\mathrm{v}}$ are fitted. The value of the AMF CF 
$a$ is mainly determined by the $\mathrm{O}_{2}$ absorption features in the fitting window. It serves as a first-order correction factor for variations in, for example, cloud cover and surface albedo, with respect to the model atmosphere, assumed within the radiative transfer calculations (i.e., a cloud-free tropical background atmosphere, a surface albedo of 0.05 and a surface elevation of $0 \mathrm{~km}$ ). This correction is expected to work well when the air mass factors for $\mathrm{O}_{2}$ and water vapour are affected by such variations in a similar way.

The SCIAMACHY-ESA total WVC product excludes measurements for which the AMF CF is smaller than 0.8 or where the solar zenith angle is larger than 88 degrees. For this study SCIAMACHY total water vapour column data covering the 18-month period from February 2010 to mid-August 2011 are used.

\subsubsection{SRON product, version 7.4.1, iterative maximum likelihood method}

The iterative maximum likelihood method (IMLM) developed by Netherlands Institute for Space Research (SRON) for retrieving trace gas columns from the near-infrared is used to derive total water vapour columns (Schrijver et al., 2009). The IMLM is applied in the wavelength range between 2353 and $2368 \mathrm{~nm}$, and because of the overlapping $\mathrm{H}_{2} \mathrm{O}, \mathrm{CO}$ and $\mathrm{CH}_{4}$ absorption lines in this region all three species are retrieved simultaneously. The IMLM (version 6.3) is described in detail in Gloudemans et al. (2008). It is based on scaling a priori atmospheric profiles, and a model of the expected detector signal is fitted to the measurements by adjusting the total column amounts of the trace gases $\left(\mathrm{H}_{2} \mathrm{O}, \mathrm{CO}\right.$ and $\left.\mathrm{CH}_{4}\right)$ that play a role in this particular retrieval window (Schrijver and Gloudemans, 2008; Schrijver et al., 2009). Water vapour and temperature profiles used in the scaling procedure are from collocated ECMWF analysis. All subsequent updates performed in version 7.4 are described in detail in Gloudemans et al. (2009). One of these updates is the use of a different spectroscopic database of $\mathrm{H}_{2} \mathrm{O}$ and $\mathrm{CH}_{4}$ for calculating the cross sections and line broadening (Gloudemans et al., 2009). Schrijver et al. (2009) found that using this updated spectroscopic parameters for $\mathrm{H}_{2} \mathrm{O}$ leads to an improvement in the IMLM WVC product when comparing it with ECMWF model data.

The retrieval has no cloud correction, so it is expected that errors generally are smaller for cloud-free conditions than for (partly) cloudy conditions, when a major part of the water vapour column is hidden below the clouds. In the case of cloud-free conditions, the signal-to-noise ratio of the measurement is closely related to the surface albedo. This leads to smaller errors for measurements taken over land than over ocean (Schrijver et al., 2009).

Therefore the first comparison in Sect. 4 is performed for cloud-free pixels over land only. The cloud filter included in the product is based on the SCIAMACHY polarization measurement device (PMD) Identification of Clouds and Ice/snow (SPICI) cloud filter as described by Krijger et al. (2005). This method distinguishes between cloud-free and partly cloudy scenes (de Laat et al., 2007) and in general provides an upper estimate of the observed cloud cover. An additional check on the cloud filter is performed by comparing the simultaneously retrieved methane columns with the expected methane columns based on the ECMWF surface pressure. Cases where the retrieved methane measurements are more than $10 \%$ below the expected value, taking into account surface pressure and elevation, are not included. The usefulness of this additional methane filter has been shown by Schrijver et al. (2009). For the comparisons with radiosondes, the two years of 2004 and 2009 of SCIAMACHY-IMLM total WVC data are used.

\section{Comparison of SCIAMACHY-ESA WVC with radiosondes}

For the comparison of water vapour column measurements between SCIAMACHY-ESA WVC data and the radiosonde data, the following collocation criteria were used: a spatial difference of less than $100 \mathrm{~km}$ (as calculated from the centre of a SCIAMACHY pixel) and a time difference of less than $3 \mathrm{~h}$. Using these criteria a total of 50470 individual measurements were found over the 18 month time period from February 2010 to mid-August 2011. Time series of the global daily mean difference between the two data sets and standard deviations are shown in Fig. 2. Gaps in the time series indicate missing data (in total 84 days) from either the SCIAMACHY or radiosonde water vapour data sets. The SCIAMACHYESA WVC amounts are overall smaller than those of the radiosondes. A small seasonal variation is evident with more spread during July-August and slightly larger global daily differences of roughly $0.15 \mathrm{~g} \mathrm{~cm}^{-2}$, compared to WVC values during the rest of the year. A generally good agreement (correlation coefficient $r=0.89$ ) between all individual collocated cases of the data sets is found with a mean difference of $-0.32( \pm 0.01) \mathrm{g} \mathrm{cm}^{-2}$, consistent with values reported by Mieruch et al. (2010), when comparing the SCIAMACHY AMC-DOAS version 1.0 from the University of Bremen to $\mathrm{SSM} / \mathrm{I}$ data. The scatter of the data is $0.69 \mathrm{~g} \mathrm{~cm}^{-2}$, slightly larger than previous comparisons performed between AMCDOAS and ECMWF model water vapour data (Noël et al., 2005), but it should be noted that the scatter reported by Noël et al. (2005) was derived for global daily means instead of individual collocations as done here. The scatter is slightly less ( standard deviation $=0.6 \mathrm{~g} \mathrm{~cm}^{-2}$ ) when considering only cases where the cloud fraction is equal to zero (10022 individual collocations). In this case a mean difference of $0.03( \pm 0.01) \mathrm{g} \mathrm{cm}^{-2}$ is found. The cloud parameters used in this section are derived from the SCIAMACHY operational products. Cloud coverage is retrieved using the Optical Cloud Recognition Algorithm (OCRA) (Loyola et al., 2007), and Semi-Analytical Cloud Retrieval Algorithm (SACURA) 


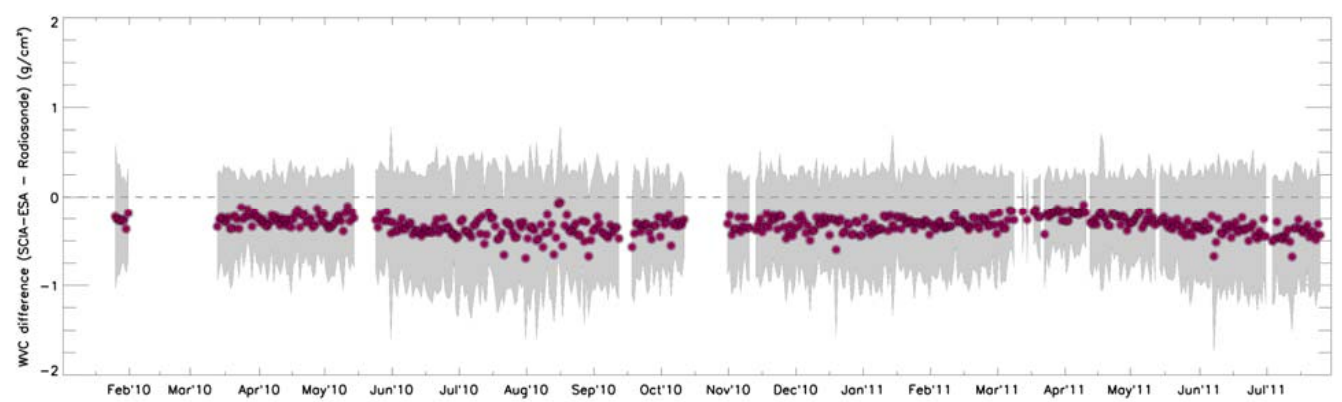

Fig. 2. The global daily difference between SCIAMACHY-ESA WVC amounts and radiosonde WVC as a function of time (1 February 2010 to 10 August 2011). Each purple circle indicates the daily mean WVC difference (SCIAMACHY-ESA minus radiosonde) per day, where the number of measurements per radiosonde station has been used as a weight. Vertical grey lines indicate the standard deviation.
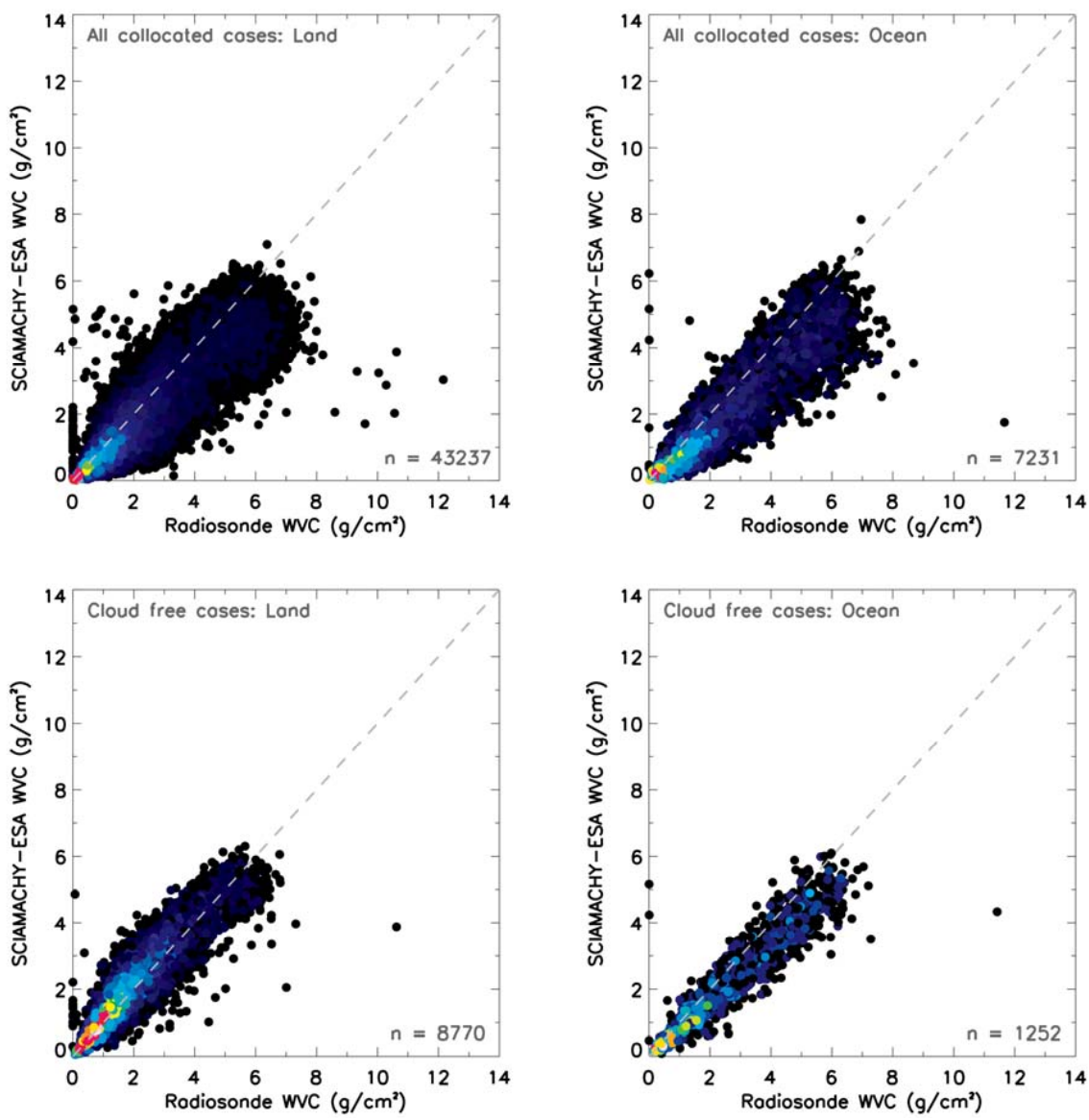

Fig. 3. Comparison between SCIAMACHY-ESA and radiosonde WVC amounts for all individual collocated cases. The top two figures are for all individual cases (all cloud fractions) over land (left) and over the ocean (right). For all cloud cases a mean bias of $-0.3 \mathrm{~g} \mathrm{~cm}{ }^{-2}$ $( \pm 0.003)$ is found for cases over land and a mean bias of $-0.5 \mathrm{~g} \mathrm{~cm}^{-2}( \pm 0.02)$ for ocean cases. The bottom two figures indicate cases selected where the SCIAMACHY-ESA cloud fraction is equal to zero, for cases over land (left) and ocean (right). For cloud-free cases a mean bias of $0.09 \mathrm{~g} \mathrm{~cm}^{-2}( \pm 0.01)$ is found for cases over land and a mean bias of $-0.43 \mathrm{~g} \mathrm{~cm}^{-2}( \pm 0.02)$ for cases over ocean surfaces.

(Kokhanovsky et al., 2005) is used to derive cloud optical thickness and cloud top height. The above radiosonde and SCIAMACHY-ESA WVC comparisons are shown in Fig. 3, for all collocated cases and for cloud-free collocated cases.
In Fig. 3 the results are further divided according to measurements taken over land and ocean surfaces.

To identify what could be responsible for the differences in WVC amounts as observed in Fig. 3, the bias as a function of several parameters, including various cloud properties, is 

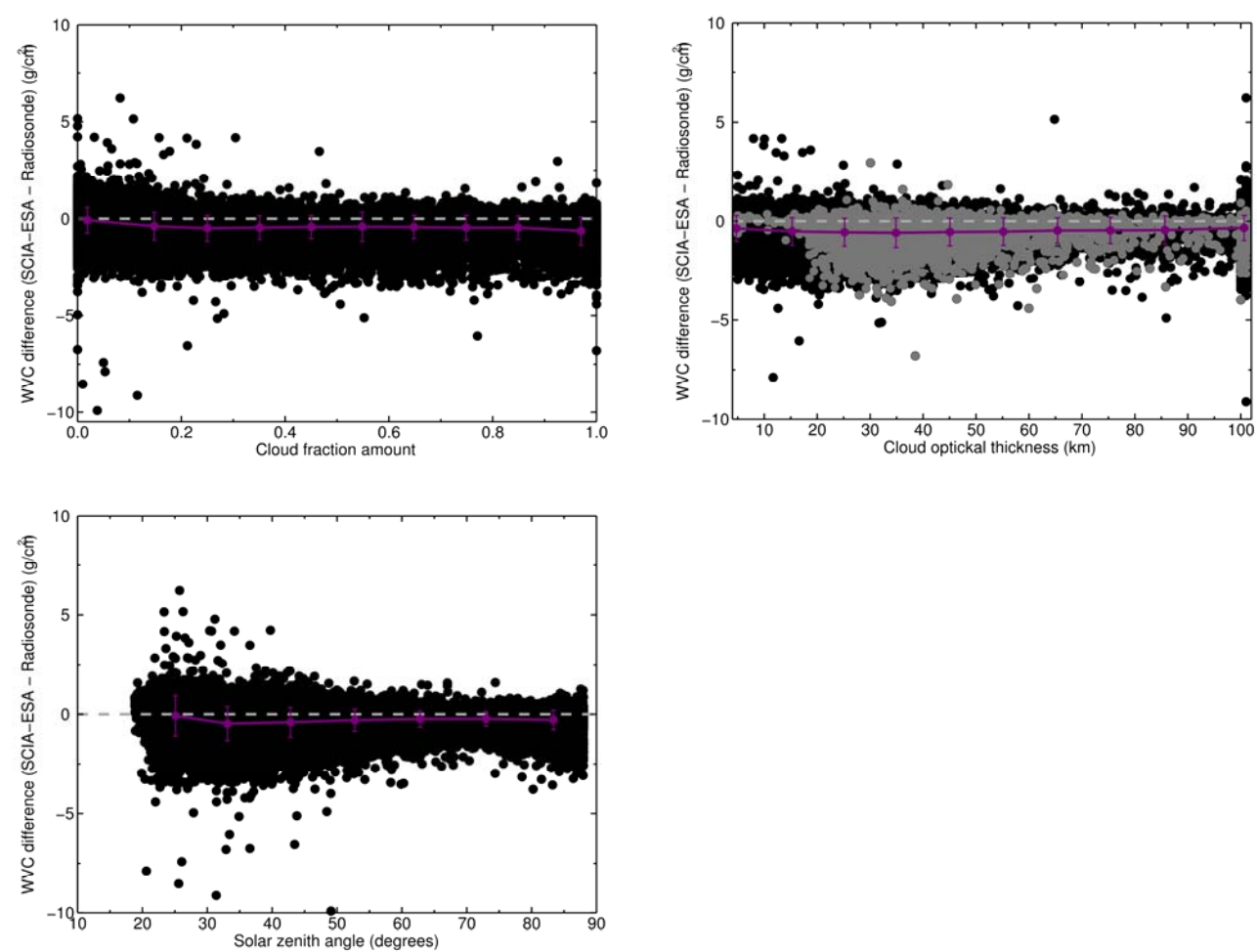

Fig. 4. SCIAMACHY-ESA and radiosonde WVC differences (SCIAMACHY-ESA minus radiosonde amounts) as a function of several parameters. WVC difference as function of cloud fraction amount (top left). Purple points indicate the mean WVC difference for 10 bins. WVC difference as a function of cloud optical thickness (top right). Purple points show the mean WVC difference for 10 bins. Measurement cases where the cloud cover fraction is larger than or equal to 0.9 are indicated in grey. WVC difference as a function of SCIAMACHY solar zenith angle (bottom left). Purple points indicate the mean WVC difference for 7 bins.

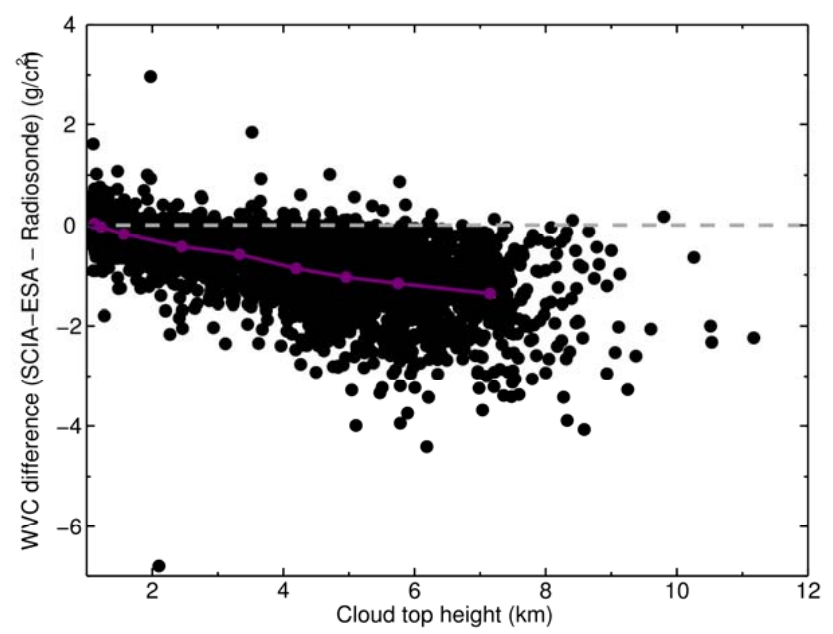

Fig. 5. SCIAMACHY-ESA and radiosonde WVC differences as a function of cloud top height, for all cases with a cloud cover fraction greater than or equal to 0.9. Purple points indicate the mean WVC difference for 9 bins with an equal number of data points (408 per bin). Note that the two bins for the smallest cloud top heights almost overlap. analysed. Investigating the bias as a function of solar zenith angle, cloud optical depth and cloud fraction (other than selecting for cloud-free cases only as done above) does not show a strong relation between these parameters and the WVC differences (Fig. 4). This suggests that the AMF CF on average works well for variations in the parameters such as solar zenith angle with respect to the assumptions in the radiative transfer calculations (see Sect. 2.2.1). A strong dependence is found when investigating the bias as a function of cloud top height during cloudy conditions. In Fig. 5 this relation is plotted for all points with a cloud cover fraction more than or equal to 0.9 . For cloud top heights larger than approximately $2 \mathrm{~km}$, the bias increases rapidly with increasing cloud top heights. A likely explanation for this increasing bias with increasing cloud top height during very cloudy conditions can be found in the very different vertical profile shapes of $\mathrm{O}_{2}$ and water vapour. $\mathrm{O}_{2}$ is well-mixed in the atmosphere, while water vapour rapidly decreases with altitude. In the presence of cloud, the cloud shields the water vapour and $\mathrm{O}_{2}$ below it, and the optical thickness for both decreases. Due to the differences in profile shape, the optical thickness of water vapour decreases more than the optical thickness of $\mathrm{O}_{2}$, and this will lead to an AMF CF which is too large (see Eq. 1), and a retrieved water vapour column which is 


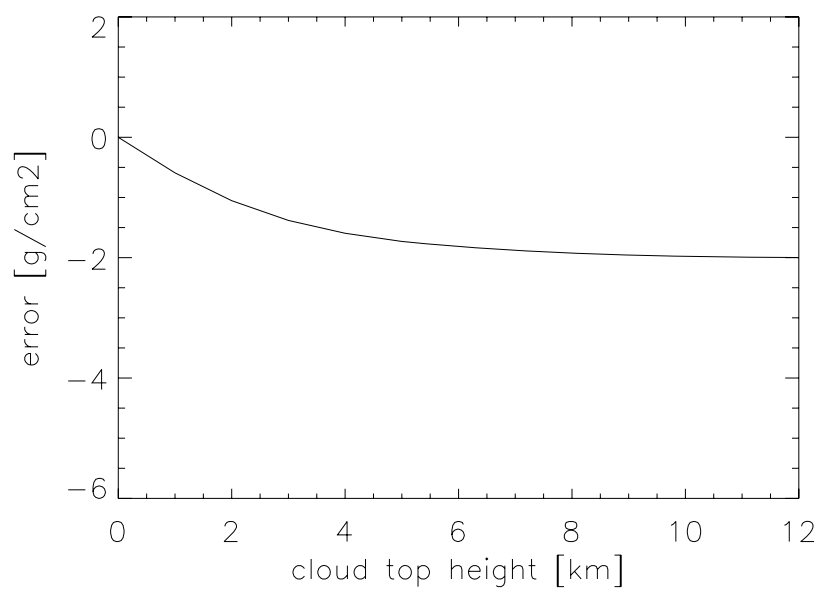

Fig. 6. Estimate of the error in the water vapour column as a function of cloud top height, as calculated with the DAK radiative transfer model for a mid-latitude summer atmospheric profile (using a total water vapour column of $2 \mathrm{~g} \mathrm{~cm}^{-2}$ ).

too small. This effect is illustrated in Fig. 6, which shows an estimate of the error in the water vapour column as a function of cloud top height, as calculated with the Doubling-Adding KNMI (DAK) radiative transfer model (de Haan et al., 1987; Stammes, 2001).

A relationship between the bias in WVC and cloud properties was also reported by Mieruch et al. (2010). They found that the average bias between GOME/SCIAMACHY water vapour and the HOAPS product over ocean depends on monthly mean cloud water path, for cases where the cloud water path was smaller than $30 \mathrm{~g} \mathrm{~m}^{-2}$ (i.e. for $12 \%$ of the data). Mieruch et al. (2010) concluded that this bias is caused by the AMF CF, which does not adequately compensate for the occurrence of clouds over the ocean. The results found here are consistent with the findings of Mieruch et al. (2010). However, we can refine the conclusion: for clouds below $2 \mathrm{~km}$, the AMF CF performs quite well. From Fig. 7 it can be seen that there is a relation between the average cloud top pressure and cloud water path. The cloud water path is a function of the vertical extent of the cloud, and this can explain the dependence of the mean bias on cloud water path as found by Mieruch et al. (2010). Given that cloud water path is not one of the cloud parameters included with the SCIAMACHY-ESA WVC product, it can be advantageous to use cloud top height directly (which is included with the SCIAMACHY-ESA product) as a selection criterion when selecting WVC data.

Figure 8 shows the average difference between SCIAMACHY-ESA and radiosonde WVC as a function of the AMF CF. For values above 1.0, the average difference does not significantly differ from 0 , suggesting that in these situations the behaviours of the optical thickness of water vapour and oxygen are somewhat similar. However, for smaller values of the AMF CF, which typically occur
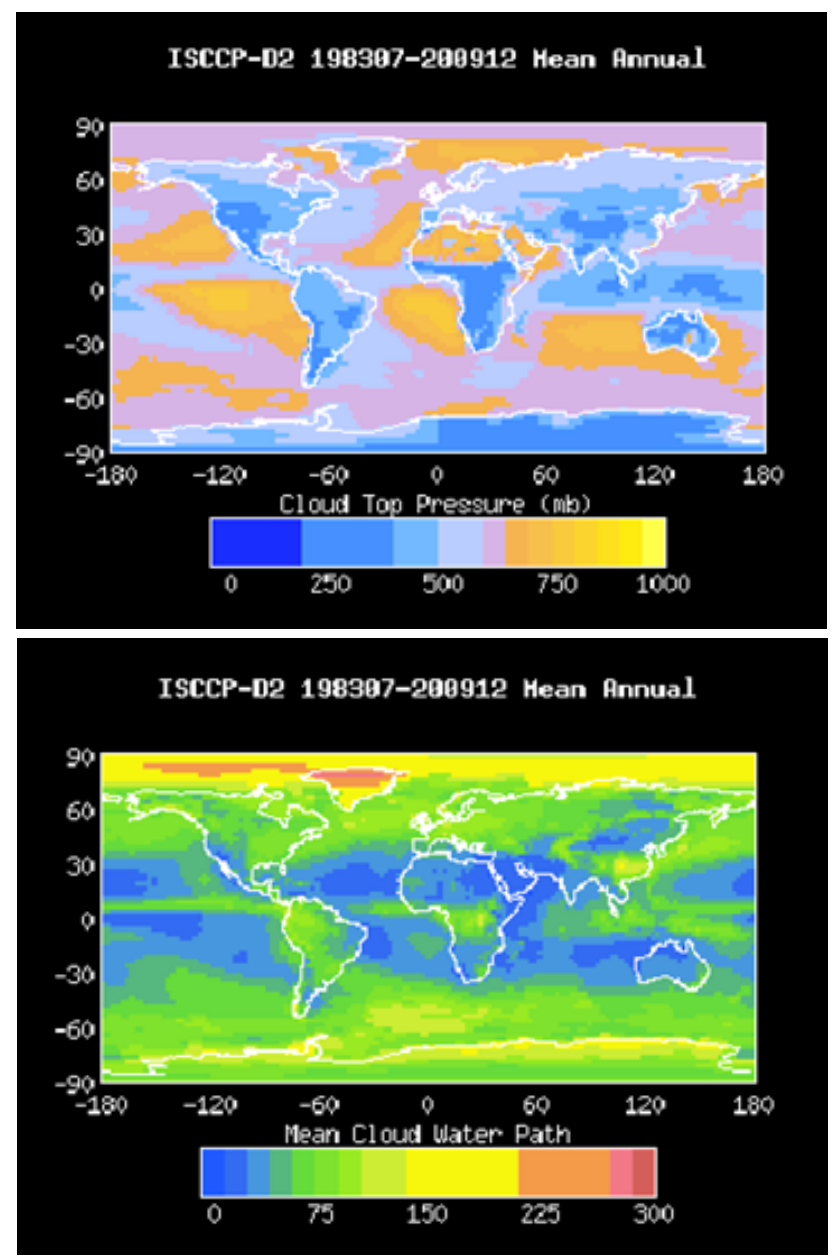

Fig. 7. Global mean annual ISCCP cloud top pressure (left) and mean cloud water path amount (right) (http://isccp.giss.nasa.gov/ products/browsed2.html).

in the presence of (high) clouds, the AMF CF should in fact be even smaller to account for the difference in profile shapes of water vapour and oxygen, as argued above. Table 1 summarizes the results when applying various selection criteria based on the cloud fraction, cloud height and the AMF CF. The choice of selection criteria will depend on the intended use of the data. From Table 1 it can be concluded that for most instances it would be beneficial to use either the AMF CF $(\geq 0.95)$ or the cloud height $(\leq 2 \mathrm{~km})$ as selection criteria. Selecting according to either of these criteria leads to an improved bias, scatter and correlation. It should be kept in mind that filtering with cloud parameters included in the SCIAMACHY-ESA product can lead to systematic biases associated with errors in these parameters being introduced. A third option is to select only cases with measurements performed during cloud-free conditions. However this largely reduces the number of available data points.

Examining the WVC measurements over land and ocean shows a noticeable disparity between the WVC differences 
Table 1. Applying various selection criteria on the SCIAMACHY-ESA and radiosonde WVC data sets. The number of cases in selection, mean WVC difference, standard deviation and correlation coefficient are given in each column.

\begin{tabular}{lrrrr}
\hline Selection criteria & $\begin{array}{r}\text { No. of cases } \\
\text { in selection }\end{array}$ & $\begin{array}{r}\text { WVC mean } \\
\text { difference } \\
\left(\mathrm{g} \mathrm{cm}^{-2}\right)\end{array}$ & $\begin{array}{r}\text { Standard } \\
\text { deviation }\end{array}$ & $\begin{array}{r}\text { Correlation } \\
\text { coefficient } R\end{array}$ \\
\hline All individual cases & 50470 & -0.32 & 0.69 & 0.89 \\
Cloud height $\leq 2 \mathrm{~km}$ or cloud fraction $\leq 0.2$ & 33518 & -0.13 & 0.57 & 0.92 \\
AMF CF $\geq 0.95$ & 33107 & -0.09 & 0.48 & 0.92 \\
Cloud height $\leq 2 \mathrm{~km}$ & 24924 & -0.05 & 0.5 & 0.93 \\
Cloud fraction $=0$ & 10022 & 0.03 & 0.6 & 0.89 \\
\hline
\end{tabular}

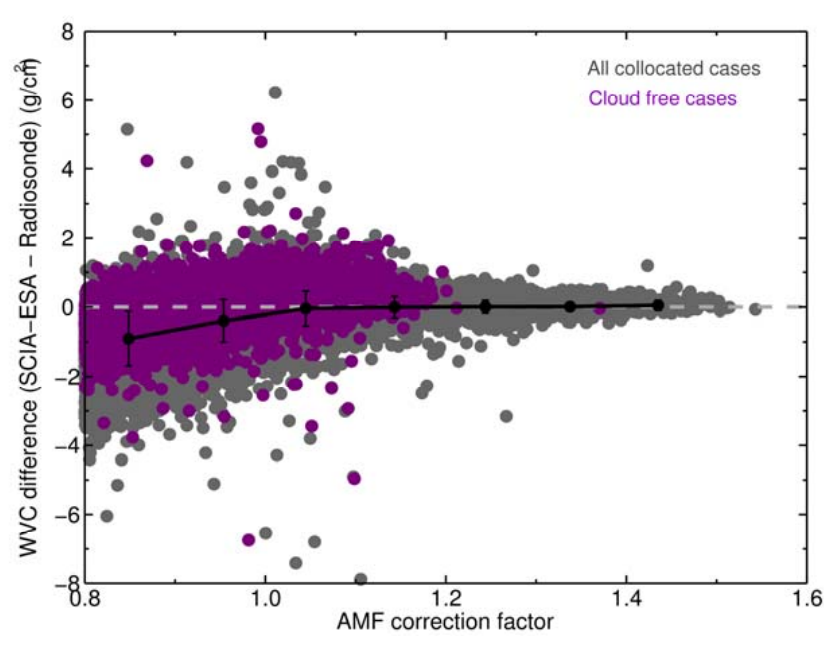

Fig. 8. SCIAMACHY-ESA and radiosonde WVC differences for all individual collocated cases shown as a function of the AMF CF. Measurements where the SCIAMACHY-ESA cloud fractions are equal to zero are indicated in purple. Grey points indicate all other cloud fraction cases. Black indicates the mean WVC difference of binned categories (AMF CF values at intervals of 0.1 ), and vertical black bars indicate the standard deviation from this mean.

over these surfaces. The mean WVC differences shown in Fig. 9 are for each of the collocated radiosonde stations for the 18-month period for cloud-free conditions (according SCIAMACHY operational cloud products). It should be noted that radiosonde measurements over the ocean are limited, and many stations are close to coastal areas. The SCIAMACHY topography is used to distinguish between the land and ocean SCIAMACHY-ESA measurements. Radiosonde stations are designated as land (or ocean) stations if more than $90 \%$ of the collocated SCIAMACHY-ESA measurements occur over land (or ocean). In general mostly negative values are found over the ocean and positive values over land. The weighted mean WVC difference amounts to $0.11 \mathrm{~g} \mathrm{~cm}^{-2}$ over land and $-0.49 \mathrm{~g} \mathrm{~cm}^{-2}$ over ocean, where the number of measurements per radiosonde station has been used as a weight. The difference in WVC measurements performed over land and ocean surfaces during

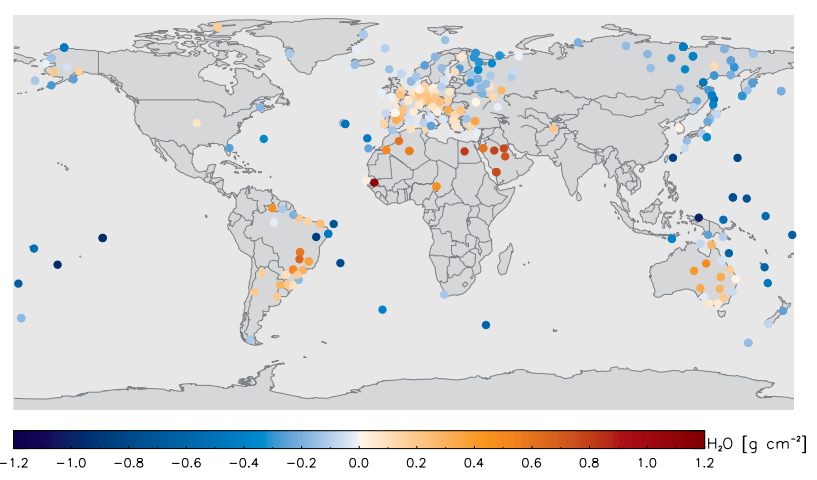

Fig. 9. SCIAMACHY-ESA and radiosonde mean WVC differences (SCIAMACHY-ESA minus radiosonde WVC amounts) for the 18-month period for cloud-free conditions. Each circle denotes the location of a radiosonde station, and the colour indicates the mean WVC difference between the radiosonde and the collocated SCIAMACHY-ESA WVC measurements, where the number of measurements per radiosonde station has been used as a weight.

cloud-free conditions can also be seen in Fig. 3 (bottom). The SCIAMACHY-ESA WVC measurements are further compared to WVC data from ECMWF over land and ocean surfaces. The SCIAMACHY-ESA WVC amounts are compared with ECMWF data for a 1-month period for cloud-free conditions (according to SPICI cloud filter, see Sect. 2.2.2) where both data sets have been averaged to a ground pixel size ranging from $120 \mathrm{~km} \times 30 \mathrm{~km}$ to $240 \mathrm{~km} \times 30 \mathrm{~km}$ (at higher latitudes) (Fig. 10). The result similarly indicates a division between land and oceans, with positive bias over land and negative bias over the ocean ranging between values of $1 \mathrm{~g} \mathrm{~cm}^{-2}$ over land to $-1 \mathrm{~g} \mathrm{~cm}^{-2}$ over oceans. A possible cause for this land-ocean disparity is most likely due to the difference in surface albedos. The AMC-DOAS method assumes an albedo of 0.05 (see Sect. 2.2.1). An error analysis performed by Noël et al. (2004) showed that retrievals with surface albedos higher than this assumed albedo can lead to larger retrieved WVC amounts. A positive bias of roughly $12 \%$ can be found over land surfaces with an albedo of 0.3 , and this bias increases with increasing albedos (Noël et al., 2004). 


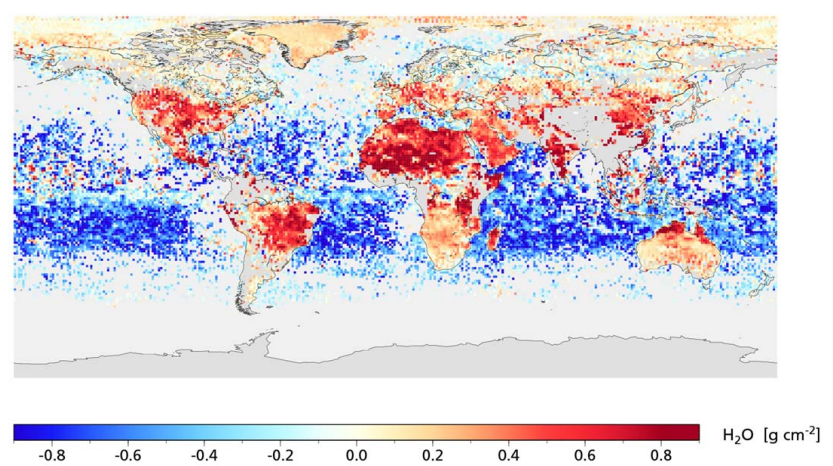

Fig. 10. SCIAMACHY-ESA and ECMWF mean WVC differences (SCIAMACHY-ESA minus ECMWF WVC amounts) for June 2005 for cloud-free conditions selected according to the SPICI cloud products. Both data sets have been averaged to a ground pixel size of approximately $120 \mathrm{~km} \times 30 \mathrm{~km}$.

\section{Comparison of SCIAMACHY-IMLM WVC with radiosondes}

The same distance and time collocation criteria as described in Sect. 3 and used for comparing ESA WVC amounts with those from radiosondes are used here for the SCIAMACHYIMLM WVC amounts. A number of selection criteria as suggested by Schrijver et al. (2009) are applied to the collocated measurement data for the two years of 2004 and 2009. This includes filtering the data to include only cloud-free cases by selecting data according to the SPICI cloud product and including the additional criterion of the simultaneously retrieved methane total column (described in Sect. 2.2.2, from here onwards simply referred to as SPICI), excluding data measurements performed over the ocean as well as measurements with an average signal strength below 100 binary units per detector pixel $\left(\mathrm{BU} \mathrm{px}^{-1}\right)$. When filtering the collocated data purely according to its quality flag and excluding cases below a signal level of $100 \mathrm{BU} \mathrm{px}^{-1}$, a total of 48844 cases are found for the 2-year period (2004 and 2009). When further selecting from these data by only including cases over land and cloud-free conditions according to the SPICI cloud product, a total number of 6590 cases remain. Finally applying the additional methane column criteria, as was done in the study of Schrijver et al. (2009), only 3489 collocations are found. For this selection, the individual cases compare well (Fig. 11), and a mean difference of 0.08 $( \pm 0.007) \mathrm{g} \mathrm{cm}^{-2}$ is found, consistent with the value found by Schrijver et al. (2009) when comparing daily averaged SCIAMACHY-IMLM WVC amounts with ECMWF model data globally. The standard deviation is $0.42 \mathrm{~g} \mathrm{~cm}^{-2}$, which is slightly larger than that found by Schrijver et al. (2009; generally below $0.3 \mathrm{~g} \mathrm{~cm}^{-2}$ ).

The SCIAMACHY-IMLM water vapour product is expected to have the smallest measurement noise error when the measured signal strength is relatively large. In principle,

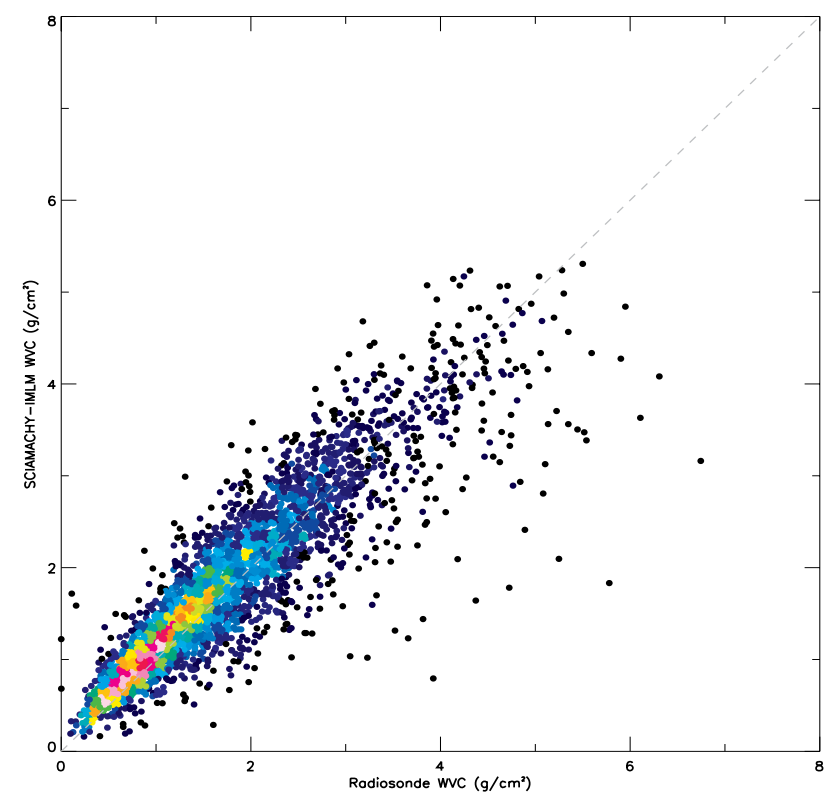

Fig. 11. Comparison between all individual collocated cases of SCIAMACHY-IMLM and radiosonde WVC amounts for the years of 2004 and 2009. The SCIAMACHY-IMLM data selection is filtered to include only land measurements taken during cloud-free conditions (according to SPICI cloud product) with the additional methane column criteria applied (see Sect. 2.2.2), and excluding cases with signal level strength below $100 \mathrm{BU} \mathrm{px}^{-1}$.

the presence of clouds will lead to larger signals and thus to smaller measurement noise errors. But clouds also shield part of the water vapour column, so that the most accurate total water vapour column retrieval is expected under cloud-free conditions and areas with bright surfaces. The SCIAMACHY-IMLM WVC measurement noise error shows a clear dependence on the signal strength (Fig. 12), indicating larger measurement noise errors for cases with lower signal strengths. The increase in the measurement noise error from the year 2004 to 2009 can be attributed to detector degradation caused by radiation damage to the individual detector pixels (Kleipool et al., 2007). Gloudemans et al. (2008) showed a dependence of the measurement noise error on the surface albedo for $\mathrm{CO}$ and $\mathrm{CH}_{4}$. For cases with low albedo values, a large measurement noise error is thus expected, for example measurements taken over cloud-free oceans. The mean bias and the standard deviation between the WVC amounts of SCIAMACHY-IMLM and that of radiosondes are related to the SCIAMACHY-IMLM signal strength, as can be seen in Fig. 13. The black lines in the figure indicate cases chosen according to the SPICI cloud-free criterion. The red lines are for cases where FRESCO+ (Fast Retrieval Scheme for Clouds from the Oxygen A-band) (Wang et al., 2008) cloud fraction is smaller than 0.02. FRESCO+ data were obtained from TEMIS (www.temis.nl). For this selection only $4 \%$ of the points have signal strengths larger than 


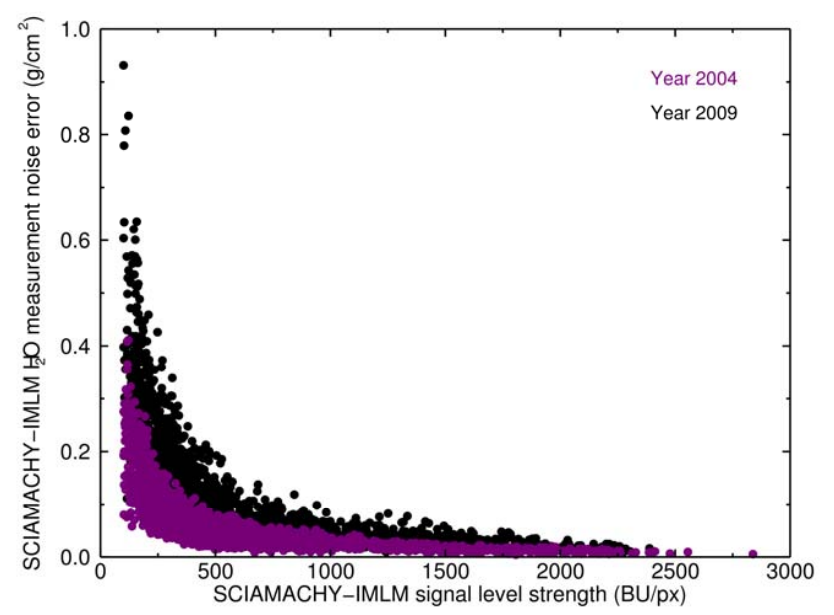

Fig. 12. SCIAMACHY-IMLM WVC measurement noise error as a function of the signal strength for two years of 2004 and 2009 (note that in the figure some values in purple overlap those in black). The data used in this figure are for cloud-free measurement cases with the additional methane filter applied (see Sect. 2.2.2) and a signal level strength above $100 \mathrm{BU} \mathrm{px}^{-1}$.

$1000 \mathrm{BU} \mathrm{px}^{-1}$, compared to $21 \%$ of the selection based on the SPICI cloud-free criterion. The largest signal strengths most likely indicate the presence of some small or scattered clouds still present in the selection. The FRESCO+ cloud parameters are averaged over the ground pixels to match the larger SCIAMACHY-IMLM water vapour ground pixel. For cloud-free conditions (FRESCO+ cloud fraction smaller than 0.02) SCIAMACHY-IMLM WVCs are consistent with those integrated from radiosonde WVC amounts, with a random uncertainty depending on the SCIAMACHY signal strength, both for pixels over land and over ocean. Also this systematic bias seems to depend on signal strength. Using cloud parameters from FRESCO+ as opposed to those of SPICI to filter for cloud-free conditions leads to less scatter and a slightly smaller mean bias.

\subsection{Partial water vapour columns above cloud over ocean surfaces}

During cloudy conditions the SCIAMACHY-IMLM WVC product does not correct for any water vapour below the clouds and the product is best used when limited to cloudfree conditions over land surfaces, although excluding all ocean measurements largely reduces the number of useable data. The majority of ocean cases are eliminated by filtering data according to the signal level strength (below $100 \mathrm{BU} \mathrm{px}^{-1}$ ). These measurements are not considered accurate enough to be used, due to low surface albedo of ocean surfaces leading to a low signal-to-noise ratio and therefore larger errors. But scenes with sufficient cloud have a higher albedo than that of ocean surfaces (typically 0.3 to 0.5 as opposed to smaller than 0.01 ). This higher cloud

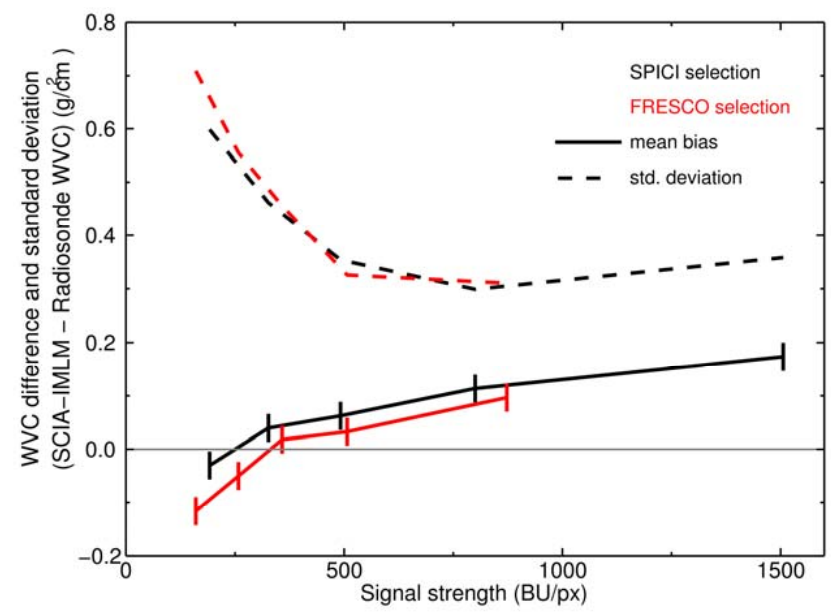

Fig. 13. The mean difference (solid line) and the standard deviation (dashed line) between SCIAMACHY-IMLM and radiosonde WVC amounts as a function of the SCIAMACHY-IMLM signal strength. For the black lines the cloud-free condition is based on SPICI (700 collocations per bin), for the red lines on FRESCO+, requiring a cloud fraction < 0.02 (407 collocations per bin). SCIAMACHYIMLM cases included in this selection are for both land and ocean measurements, excluding cases with signal strength below $100 \mathrm{BU} \mathrm{px}^{-1}$.

reflectance leads to larger signals and thus smaller measurement noise errors. Therefore including ocean measurements during cloudy conditions in the data selection could be advantageous. As the SCIAMACHY-IMLM product does not correct for water vapour below the cloud, in this instance only the partial WVC that is measured above the cloud and over ocean surfaces can be used. Gloudemans et al. (2009) used an approach whereby SCIAMACHY (partial) CO column information above clouds over the ocean can be used. In that study it was shown that the cloud top height can be estimated using the $\mathrm{CH}_{4}$ column which is retrieved from the same spectral window together with the water vapour and $\mathrm{CO}$ columns. These estimated cloud top heights were then used to determine the partial $\mathrm{CO}$ columns that are observed above the cloud.

The same steps are applied here in order to compare the partial SCIAMACHY-IMLM WVC measured above the cloud over the ocean. Similar to the study of Gloudemans et al. (2009), cloudy ocean measurements are chosen where the cloud fractions are greater than 0.2. Here we use FRESCO+ to determine the cloud fraction. The cloud top heights are determined using the ratio of the measured SCIAMACHY $\mathrm{CH}_{4}$ column over the expected value of the $\mathrm{CH}_{4}$ column (see Sect. 2.2.2), multiplied by the surface pressure (Gloudemans et al., 2009). Selecting cloudy cases according to a cloud fraction larger than 0.2 guarantees that some cloud is present. The high cloud reflectance compared to the very low ocean surface reflectance means that the cloud-free part of the WVC retrieval does not contribute significantly to the overall 


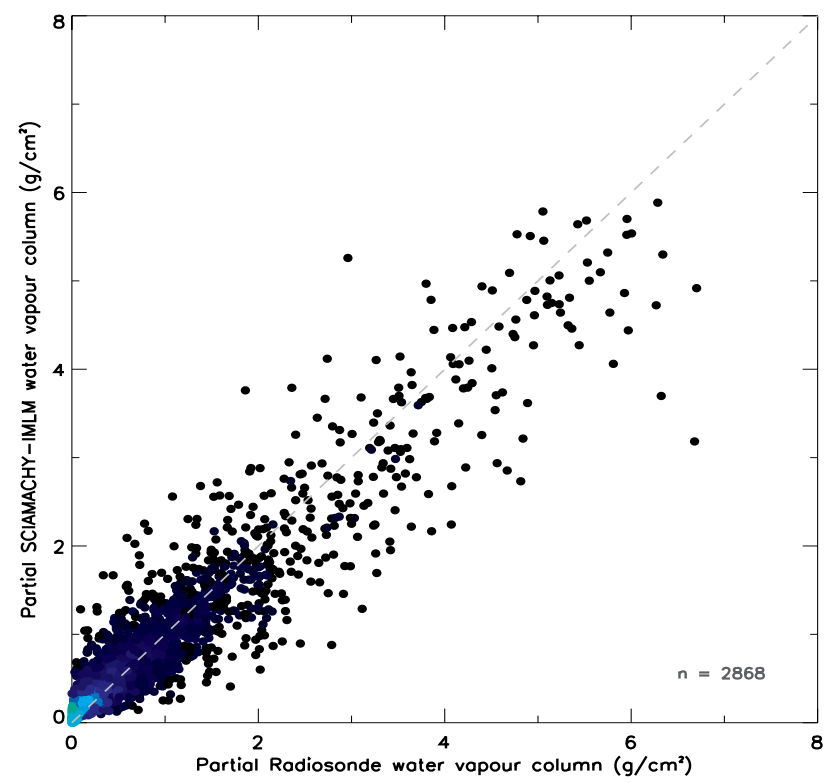

Fig. 14. Comparison between SCIAMACHY-IMLM partial WVC and radiosonde partial WVC amounts for measurement cases over the ocean where SPICI cloud fraction is larger than 0.2. The radiosonde partial WVC amounts are obtained by integrating the relative humidity profile from the cloud top pressure, calculated using the SCIAMACHY $\mathrm{CH}_{4}$ column.

WVC measurement. This is also a reason why this approach works best over ocean surfaces only - for land surfaces the surface albedo is higher and no longer negligible. In addition SCIAMACHY has a large footprint size in this wavelength range, and the albedo of land surfaces can vary within one SCIAMACHY ground pixel, making it more difficult to distinguish between the cloudy and cloud-free part of the measurement (Gloudemans et al., 2009). Figure 14 shows the results for SCIAMACHY-IMLM partial WVC compared to corresponding partial radiosonde WVC. The radiosondeobtained relative humidity profile is integrated from the top of the cloud determined from the SCIAMACHY $\mathrm{CH}_{4}$ column, rather than from the ground surface as done with comparisons in previous sections. The partial WVCs compare well, and a small mean bias of $0.02 \mathrm{~g} \mathrm{~cm}^{-2}$ is found, a standard deviation of $0.34 \mathrm{~g} \mathrm{~cm}^{-2}$, and a high correlation of 0.94 . Using cloud top height as determined by SCIAMACHY $\mathrm{CH}_{4}$ columns leads to better results than using FRESCO+ cloud top height, as can be seen from Table 2. This difference in results is not necessarily related to the FRESCO+ cloud products, but more likely emphasizes that the SCIAMACHY $\mathrm{CH}_{4}$ columns, which are retrieved from the same spectral region as water vapour, provide more accurate cloud top height information. Therefore in this case it is a more appropriate product to use together with SCIAMACHY-IMLM WVC.
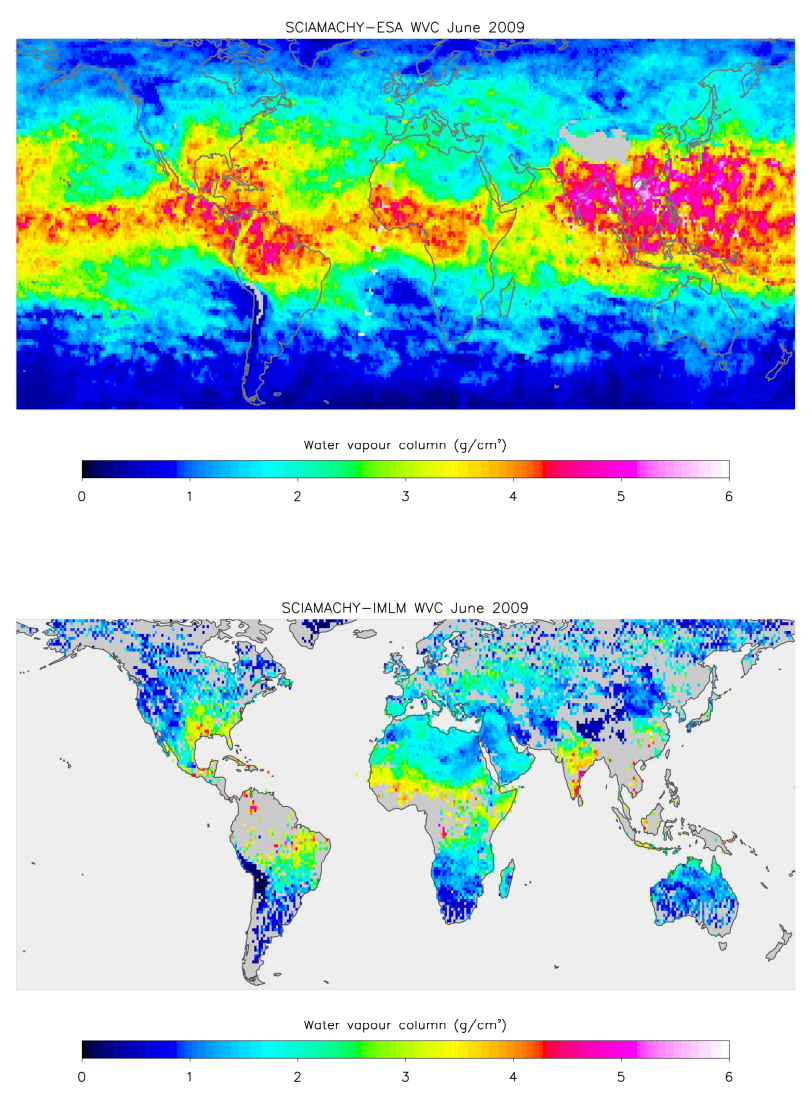

Fig. 15. SCIAMACHY-ESA (top) and SCIAMACHY-IMLM (bottom) averaged WVC amounts for the month of June 2009. In both figures each WVC product's own suggested selection criteria are used: SCIAMACHY-ESA WVC measurements are for all cloud conditions over land and ocean surfaces, and SCIAMACHY-IMLM WVC measurements are filtered according to the suggested criteria whereby only cloud-free cases over land are included, with signal level strengths larger than or equal to $100 \mathrm{BU} \mathrm{px}^{-1}$.

\section{Intercomparison between SCIAMACH AMC-DOAS and IMLM water vapour data}

A comparison between the SCIAMACHY-IMLM and SCIAMACHY-ESA water vapour data sets is performed for a 1-month period of June 2009. The water vapour column amounts averaged for this 1-month period are shown in Fig. 15. The patterns of water vapour agree well with one another, and similar features can be seen over continents. Figure 16 shows the comparison of SCIAMACHYESA WVC with SCIAMACHY-IMLM WVC amounts for this 30-day period. Here the SCIAMACHY-ESA WVC amounts and the matching operational ESA cloud fraction amounts are averaged over the ground pixels to match the larger SCIAMACHY-IMLM water vapour ground pixel size. The collocated cases are further selected to include only measurements over land with SCIAMACHY-IMLM 
Table 2. Results from comparisons between the (partial) SCIAMACHY-IMLM WVC above the cloud during cloudy conditions over ocean surfaces with partial radiosonde WVC amounts. The partial radiosonde column is obtained by integrating the radiosonde humidity profile from the top of the cloud, where the cloud top height is obtained using either FRESCO+ cloud top height (shown in top half of the table) or the cloud top height as estimated from the $\mathrm{CH}_{4}$ column (shown in bottom half of the table). In both instances the cloud fraction is determined by FRESCO+. The number of cases in selection, mean WVC difference, standard deviation and correlation coefficient are given in each column.

\begin{tabular}{lrrrr}
\hline $\begin{array}{l}\text { Selection according to } \\
\text { FRESCO+ cloud fraction }\end{array}$ & $\begin{array}{r}\text { No. of cases } \\
\text { in selection }\end{array}$ & $\begin{array}{r}\text { WVC mean } \\
\text { difference } \\
\left(\mathrm{g} \mathrm{cm}^{-2}\right)\end{array}$ & $\begin{array}{r}\text { Standard } \\
\text { deviation }\end{array}$ & $\begin{array}{r}\text { Correlation } \\
\text { coefficient } R\end{array}$ \\
\hline FRESCO+ cloud top height: & & & & \\
$>0.2$ & 2868 & 0.07 & 0.48 & 0.85 \\
$\geq 0.4$ & 1707 & -0.03 & 0.35 & 0.85 \\
$\geq 0.8$ & 467 & -0.15 & 0.38 & 0.79 \\
\hline $\mathrm{CH}_{4}$ cloud top height: & & & & \\
$>0.2$ & 2868 & 0.02 & 0.34 & 0.94 \\
$\geq 0.4$ & 1707 & 0.04 & 0.24 & 0.94 \\
$\geq 0.8$ & 467 & 0.04 & 0.19 & 0.94 \\
\hline
\end{tabular}

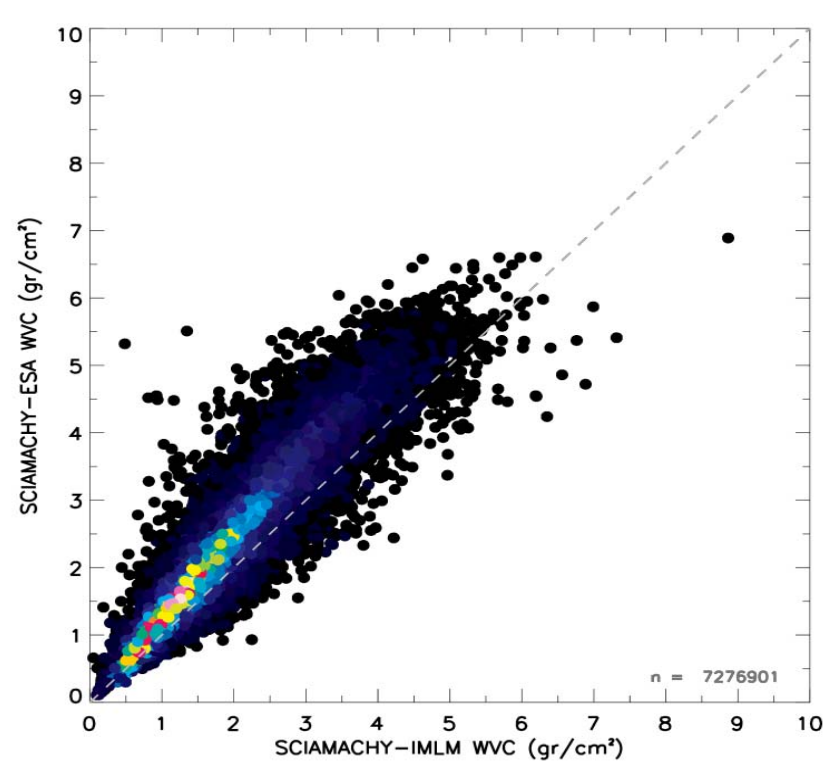

Fig. 16. Comparison between collocated SCIAMACHY-IMLM and SCIAMACHY-ESA WVC amounts for June 2009. The SCIAMACHY-ESA WVC measurements and cloud cover amounts are averaged over the SCIAMACHY-IMLM ground pixel size. Cases included in the selection are for SCIAMACHY-IMLM signal level strength larger than or equal to $100 \mathrm{BU} \mathrm{px}^{-1}$ and are limited to land measurements during cloud-free conditions where SPICI (together with the additional methane cloud filter) and the averaged ESA cloud fraction amounts are zero. A mean bias of $0.39 \mathrm{~g} \mathrm{~cm}^{-2}$ is found with a standard deviation of $0.35 \mathrm{~g} \mathrm{~cm}^{-2}$.

signal level larger than or equal to $100 \mathrm{BU} \mathrm{px}^{-1}$ and conditions which are cloud-free according to both the (averaged) ESA cloud product and the SPICI cloud product and using the additional methane criterion (described in Sect. 2.2.2). The SCIAMACHY-ESA and SCIAMACHY-IMLM WVC amounts have a high correlation $(r=0.95)$, but in general SCIAMACHY-ESA WVC amounts are higher than those of SCIAMACHY-IMLM with a percentage difference of $23 \%$. A further comparison between SCIAMACHY-ESA and SCIAMACHY-IMLM WVC data is performed by comparing both data sets with collocated radiosonde WVC amounts for the same 1-month period of June 2009 as used in the above SCIAMACHY-ESA versus SCIAMACHYIMLM comparison. The same time and distance co-location criteria used for comparisons in Sects. 3 and 4 are used here. Each SCIAMACHY-ESA and SCIAMACHY-IMLM WVC measurement is thus collocated with individual global daily radiosonde measurements performed during the 1month period. No averaging over the smaller SCIAMACHYESA ground pixels needs to be performed here, since only the SCIAMACHY-ESA or SCIAMACHY-IMLM pixel closest to the radiosonde measurement location is used. These three collocated data sets are filtered to include only cases with measurements performed over land and where the SCIAMACHY-IMLM signal level strength is larger than or equal to $100 \mathrm{BU} \mathrm{px}^{-1}$. The results of the comparisons with these three data sets for June 2009 are shown in Fig. 17 for different cloud cover selections according to either the ESA operational cloud cover product (OCRA), SPICI cloud cover product, or both cloud cover products. Both of the individual SCIAMACHY WVC data sets compare well with the collocated radiosonde WVC values (Fig. 17, top). Further comparisons of the radiosonde WVC to SCIAMACHYESA and SCIAMACHY-IMLM for the same selection of data points where both SPICI and OCRA measure cloudfree conditions are shown in Fig. 17 (bottom). This indicates that the respective mean biases are inconsistent with the above SCIAMACHY-ESA versus SCIAMACHYIMLM comparison for June 2009, or with previous comparisons in Sects. 3 and 4 with radiosonde WVC data for 

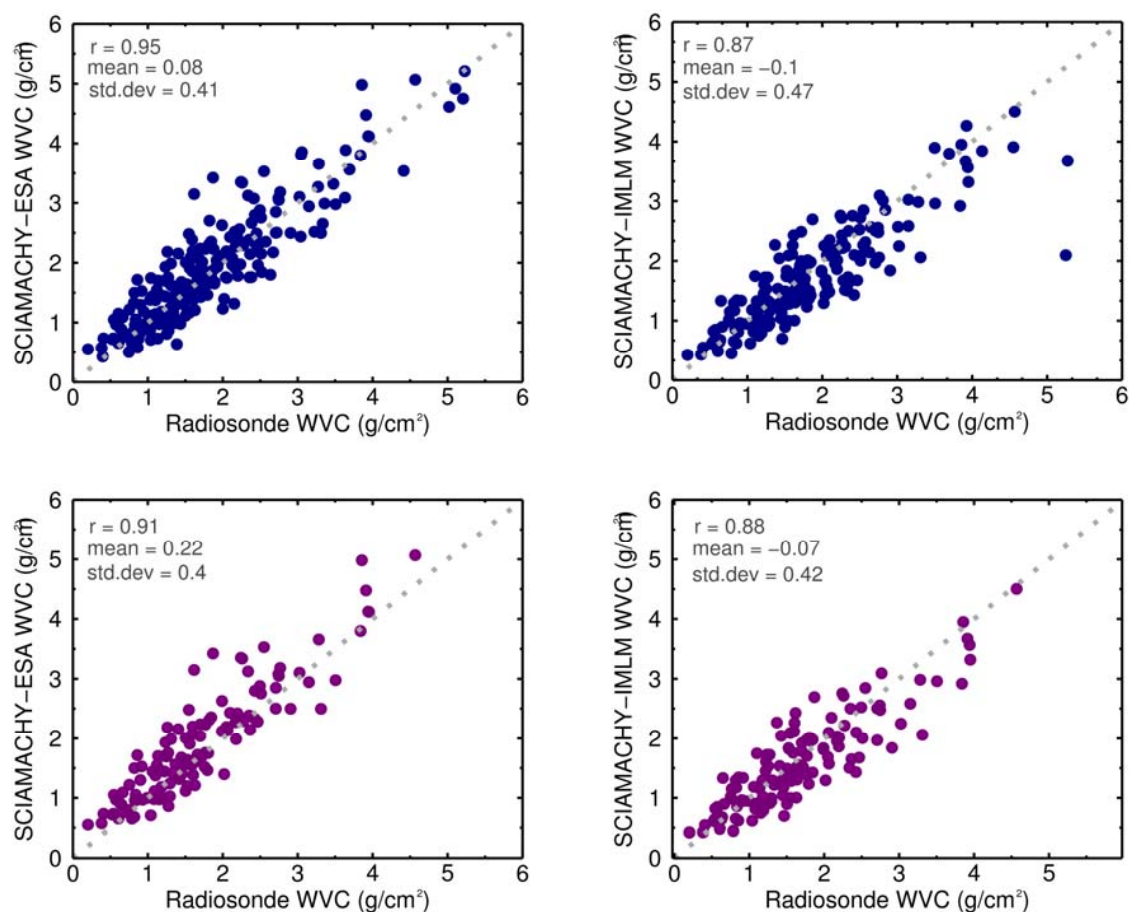

Fig. 17. Comparison between collocated radiosonde WVC and SCIAMACHY-IMLM and SCIAMACHY-ESA WVC amounts for June 2009, for measurements performed over land. The top left figure shows radiosonde WVC compared to SCIAMACHY-ESA for cloud-free conditions according to the SCIAMACHY operational cloud cover (OCRA) product. The top right figure shows the comparison between radiosonde and SCIAMACHY-IMLM WVC amounts for cloud-free conditions according to the SPICI cloud cover product. The two bottom figures indicate comparisons between collocated radiosonde WVC and SCIAMACHY-ESA (bottom left) and SCIAMACHY-IMLM (bottom right) over land for cloud-free conditions according to both SPICI and OCRA cloud cover fraction. The correlation coefficient, mean and standard deviation $\left(\mathrm{g} \mathrm{cm}^{-2}\right)$ are shown in each figure.

cloud-free cases over land and results in mean differences of $0.09 \mathrm{~g} \mathrm{~cm}^{-2}$ for SCIAMACHY-ESA and $0.08 \mathrm{~g} \mathrm{~cm}^{-2}$ for SCIAMACHY-IMLM WVC. This inconsistency appears to be caused by differences in the SPICI and OCRA cloud cover products when selecting for cloud-free conditions. Comparing OCRA cloud cover to that of FRESCO+ (Fig. 18) shows that in roughly $80 \%$ of the cases where OCRA cloud cover fraction equals zero, the FRESCO+ cloud cover amount is more than zero and indicates that some form of cloud is still present in the (OCRA) selection. This suggests that when using cloud products together with the SCIAMACHYESA WVC data, it might be more beneficial to use a supplementary or different cloud product. Selecting SCIAMACHY WVC data according to cloud-free conditions can be beneficial in some instances when using SCIAMACHYESA water vapour data and even more important when using SCIAMACHY-IMLM water vapour data. The choice of cloud product used to identify cloud-free measurements for each of the two SCIAMACHY water vapour products can play a significant role. Using different cloud products for filtering either SCIAMACHY-ESA or SCIAMACHY-IMLM WVC may introduce biases and ultimately influence the data selection leading to a variation in results, as demonstrated above.

\section{Discussion and conclusions}

The two SCIAMACHY WVC data sets used in this study are retrieved from different wavelength regions, using different retrieval methods, auxiliary data and radiation transport models. In spite of these differences, an intercomparison between the two SCIAMACHY WVC data sets has a high degree of correlation $(r=0.95)$ when filtering the data for cloud-free measurements over land.

When comparing SCIAMACHY-ESA WVC to collocated radiosonde $\mathrm{WVC}$, a good agreement is found with a mean difference of $-0.32 \mathrm{~g} \mathrm{~cm}^{-2}$ when selecting all collocated cases for both land and ocean surfaces for all cloud conditions. The mean bias $\left(0.03 \mathrm{~g} \mathrm{~cm}^{-2}\right)$ and scatter improve when considering only cases with cloud-free conditions (over both ocean and land surfaces). The bias has a clear dependence on the cloud top height and increases with increasing cloud top heights that are larger than approximately $2 \mathrm{~km}$. A likely explanation for the bias is the very different vertical profile shapes of $\mathrm{O}_{2}$ and water vapour, ultimately 

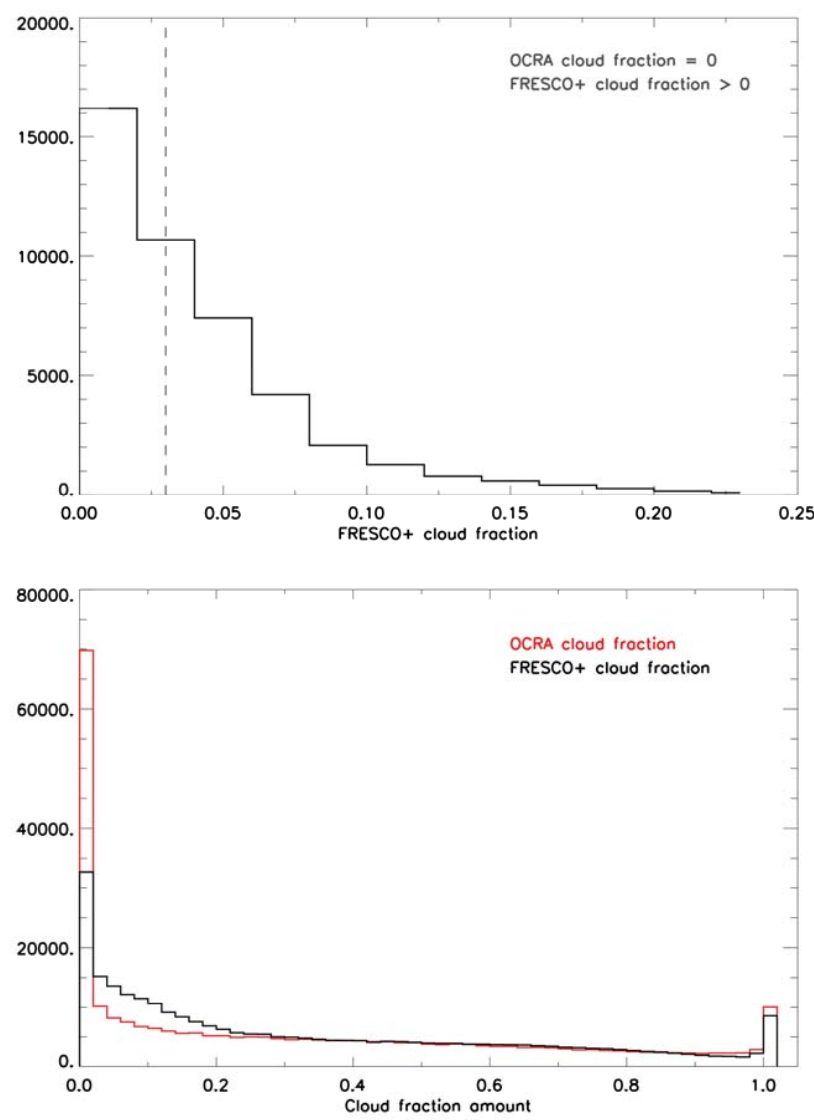

Fig. 18. Comparison between OCRA and FRESCO+ cloud cover amounts, for where OCRA cloud cover fraction equals zero. For $80 \%$ of the selected cases where OCRA cloud cover fraction equals zero, the FRESCO+ cloud cover amount is more than zero and indicates that some form of cloud is still present in the (OCRA) selection. The dashed vertical line in the top figure indicates the median FRESCO+ cloud cover fraction of 0.03 . The bottom figure indicates the number of cloud fraction cases of the OCRA (red) and FRESCO+ (black) cloud cover cases.

leading to an AMF CF which is too large. Furthermore, a division between the WVC differences over land and ocean surfaces, most likely as a result of the difference in surface albedos, is found. This land-ocean disparity is also confirmed when comparing SCIAMACHY-ESA with ECMWF WVC amounts and should be taken into account when taking zonal or global averages. The SCIAMACHY-IMLM water vapour product does not apply any correction for the amount of water vapour present below cloud. Therefore strict filtering is needed for measurements over land to select cloudfree cases. Applying the filtering criteria as suggested in Schrijver et al. (2009) to the SCIAMACHY-IMLM WVC data largely reduces the amount of useable data. Despite these restrictions, a high correlation is found when comparing these individual WVC amounts to those of radiosonde WVC. A mean difference of $0.08 \mathrm{~g} \mathrm{~cm}^{-2}$ is found for measurements over land during cloud-free conditions, consistent with the value found by Schrijver et al. (2009), but with a slightly higher standard deviation of $0.42 \mathrm{~g} \mathrm{~cm}^{-2}$ than that found by Schrijver et al. (2009). The strict filtering criteria also exclude all cloud-free measurements above ocean surfaces due to the low signal levels expected over the ocean. However, as shown in Sect. 4.1, cloudy observations over the ocean provide useful information and compare well with the corresponding partial columns obtained from the radiosondes. Here the information on cloud top height is derived from the $\mathrm{CH}_{4}$ product in the same spectral region.

Intercomparisons between the two SCIAMACHY WVC satellite products indicate that even though SCIAMACHYESA and SCIAMACHY-IMLM WVC respectively compare well with collocated radiosonde data, when comparing them with each other SCIAMACHY-ESA WVC amounts are systematically higher than those of SCIAMACHY-IMLM WVC by $23 \%$ (for measurements over land where the SCIAMACHY-IMLM signal level is larger than or equal to $100 \mathrm{BU} \mathrm{px}^{-1}$ and for cloud-free conditions as determined by both the ESA and SPICI cloud products). This difference is in large part due to the fact that the SCIAMACHY-ESA WVCs are biased high over (most of the) land. Furthermore, results show (Sect. 5) that the mean bias can be affected by the cloud product used to select for cloud-free conditions.

This highlights the importance that the choice of cloud product can have on SCIAMACHY water vapour column data when using it to filter for cloud-free measurements. In principle the AMC-DOAS method used by SCIAMACHYESA WVC corrects for the (partial) presence of clouds via the AMF correction factor. However it was shown that this correction does not always work well for higher altitude clouds (Sect. 3). Since the SCIAMACHY-IMLM water vapour product does not correct for water vapour below clouds, data must be filtered according to cloud-free conditions. Using SPICI and the additional methane column criteria when choosing cloud-free measurements is convenient, because all information is readily available within the product. However, it was shown (Sect. 4) that a better cloud-free filtering leading to less scatter and a slightly smaller mean bias with regard to radiosonde WVC can be achieved by using the FRESCO+ cloud fraction product.

For best results selection criteria should be applied to both SCIAMACHY-ESA and SCIAMACHY-IMLM WVC data sets. In order to minimize the bias, different criteria were investigated for the best selection and use of SCIAMACHY WVC data, but ultimately the choice of selection criteria will depend on the intended use of the data. As the SCIAMACHY-ESA mean WVC bias increases with increasing cloud top height, the cloud top height could be useful to filter SCIAMACHY-ESA data so as to exclude all data with high clouds. This option will result in the best mean bias, but will however decrease the amount of available data. Alternatively, if using a smaller SCIAMACHY-ESA WVC data set with limited available measurements, it would be more useful to apply a selection criterion whereby smaller AMF 
correction factors $(\leq 0.95)$ are excluded. The selection criteria for SCIAMACHY-IMLM measurements over land with cloud-free conditions are more strict and limit the number of data points.

Radiosonde water vapour column data compared with SCIAMACHY-IMLM WVC show good results when comparing measurements over land and during cloud-free scenes. One of this product's limitations is that it does not apply a correction during cloudy conditions for water vapour present below the cloud, as is done with SCIAMACHY-ESA WVC. However, there is no fundamental limitation to perform retrievals in the short-wave infrared under cloudy conditions (Vidot et al., 2012). Similar to SCIAMACHY-IMLM, only a small bias is found when comparing SCIAMACHY-ESA to radiosonde water vapour amounts during cloud-free conditions. An advantage is that the SCIAMACHY-ESA product provides water vapour measurements during cloudy conditions over both land and ocean surfaces, but the air mass correction factor used in the algorithm to correct for clouds can lead to a bias in cases with high cloud top heights. Furthermore, comparisons with radiosonde data indicate a landocean disparity. Possible correction of the air mass correction factor in the AMC-DOAS retrieval scheme or otherwise filtering of the water vapour column data, together with the future planned additions for the retrieval of water vapour in the short-wave infrared wavelength range, may further benefit water vapour column measurements from these different wavelength regions.

Acknowledgements. SCIAMACHY is a joint project of the German Space Agency (DLR) and the Netherlands Space Office (NSO) with contribution of the Belgian Space Agency. The work performed is partly financed by Netherlands Space Office via the SCIAVISIE project.

Edited by: D. Loyola

\section{References}

Bovensmann, H., Burrows, J. P., Buchwitz, M., Frerick, J., Noël, S., Rozanov, V. V., Chance, K. V., and Goede, A.: SCIAMACHY: Mission Objectives and Measurement Modes, J. Atmos. Sci., 56, 127-150, 1999.

deHaan, J. F., Bosma, P. B., and Hovenier, J. W.: The adding method for multiple scattering calculations of polarized light, Astron. Astrophys., 183, 371-391, 1987.

deLaat, A. T. J., Gloudemans, A. M. S., Aben, I., Krol, M., Meirink, J. F., van der Werf, G. R., and Schrijver, H.: SCIAMACHY carbon monoxide total columns: statistical evaluation and comparison with CTM results, J. Geophys. Res., 112, D12310, doi:10.1029/2006JD008256, 2007.

Gloudemans, A. M. S., Schrijver, H., Hasekamp, O. P., and Aben, I.: Error analysis for $\mathrm{CO}$ and $\mathrm{CH}_{4}$ total column retrievals from SCIAMACHY $2.3 \mu \mathrm{m}$ spectra, Atmos. Chem. Phys., 8, 39994017, doi:10.5194/acp-8-3999-2008, 2008.
Gloudemans, A. M. S., de Laat, A. T. J., Schrijver, H., Aben, I., Meirink, J. F., and van der Werf, G. R.: SCIAMACHY CO over land and oceans: 2003-2007 interannual variability, Atmos. Chem. Phys., 9, 3799-3813, doi:10.5194/acp-9-3799-2009, 2009.

Goff, J. A. and Gratch, S.: Low-pressure properties of water from -160 to $212 \mathrm{~F}$ : in Transactions of the American society of heating and ventilating engineers, 52nd annual meeting of the American society of heating and ventilating engineers, New York, 95$122,1946$.

Gottwald, M. and Bovensmann, H. (Eds.): SCIAMACHY - Exploring the Changing Earth's Atmosphere. Springer Heidelberg Dordrecht London New York, doi:10.1007/978-90-481-9896-2, 2011.

Kleipool, Q. L., Jongma, R. T., Gloudemans, A. M. S., Schrijver, H., Lichtenberg, G. F., van Hees, R. M., Maurellis, A. N., and Hoogeveen, R.W. M.: In-flight proton-induced radiation damage to SCIAMACHY's extended-wavelength InGaAs near-infrared detectors, Infrared Phys. Techn., 50, 30-37, 2007.

Kokhanovsky, A. A., Rozanov, V. V., Burrows, J. P., Eichmann, K.U., Lotz, W., and Vountas, M.: The SCIAMACHY cloud products: Algorithms and examples from ENVISAT, Adv. Space Res., 36, 789-799, doi:10.1016/j.asr.2005.03.026, 2005.

Krijger, J. M., Aben, I., and Schrijver, H.: Distinction between clouds and ice/snow covered surfaces in the identification of cloud-free observations using SCIAMACHY PMDs, Atmos. Chem. Phys., 5, 2729-2738, doi:10.5194/acp-5-2729-2005, 2005.

Lang, R., Casadio, S., Maurellis, A. N., and Lawrence, M. G.: Evaluation of the GOME Water Vapor Climatology 1995-2002, J. Geophys. Res., 112, D17110, doi:10.1029/2006JD008246, 2007.

Loyola, D., Thomas, W., Livschitz, Y., Ruppert, T., Albert, P., and Hollmann, R.: Cloud properties derived from GOME/ERS-2 backscatter data for trace gas retrieval, IEEE T. Geosci. Remote, 45, 2747-2758, 2007.

Mieruch, S., Schröder, M., Noël, S., and Schulz, J.: Comparison of monthly means of global total column water vapour retrieved from independent satellite observations, J. Geophys. Res., 115, D23310, doi:10.1029/2010JD013946, 2010.

Noël, S., Buchwitz, M., Bovensmann, H., Hoogen, R., and Burrows, J. P.: Atmospheric Water Vapor Amounts Retrieved from GOME Satellite Data, Geophys. Res. Lett., 26, 1841-1844, 1999.

Noël, S., Buchwitz, M., and Burrows, J. P.: First retrieval of global water vapour column amounts from SCIAMACHY measurements, Atmos. Chem. Phys., 4, 111-125, doi:10.5194/acp-4-1112004, 2004.

Noël, S., Buchwitz, M., Bovensmann, H., and Burrows, J. P.: Validation of SCIAMACHY AMC-DOAS water vapour columns, Atmos. Chem. Phys., 5, 1835-1841, doi:10.5194/acp-5-18352005, 2005.

Noël, S., Mieruch, S., Bovensmann, H., and Burrows, J. P.: Preliminary results of GOME-2 water vapour retrievals and first applications in polar regions, Atmos. Chem. Phys., 8, 1519-1529, doi:10.5194/acp-8-1519-2008, 2008.

Schrijver, H. and Gloudemans, A. M. S.: IMLM v6.3 algorithm description, Netherlands Institute for Space Research (SRON), Utrecht, the Netherlands, SRON-EOS-HS-08001, 9 pp., 2008. 
Schrijver, H., Gloudemans, A. M. S., Frankenberg, C., and Aben, I.: Water vapour total columns from SCIAMACHY spectra in the $2.36 \mu \mathrm{m}$ window, Atmos. Meas. Tech., 2, 561-571, doi:10.5194/amt-2-561-2009, 2009.

Stammes, P.: Spectral radiance modeling in the UV-visible range, in: Proceedings of the International Radiation Symposium IRS 2000: Current Problems in Atmospheric Radiation, edited by: Smith, W. L., Timofeyev, Yu. M., A Deepak Publishing, Hampton, Virginia, 385-388, 2001.

Sun, B., Reale, A., Seidel, D. J., and Hunt, D. C.: Comparing radiosonde and COSMIC atmospheric profile data to quantify differences among radiosonde types and the effects of imperfect collocation on comparison statistics, J. Geophys. Res., 115, D23104, doi:10.1029/2010JD014457, 2010.
Vidot, J., Landgraf, J., Hasekamp, O. P., Butz, A., Galli, A., Tol, P., and Aben, I.: Carbon monoxide from shortwave infrared reflectance measurements: A new retrieval approach for clear sky and partially cloudy atmospheres, Remote Sens. Environ., 120, 255-266, 2012.

Wang, J. and Zhang, L.: Systematic Errors in Global RadiosondePrecipitable Water Data from Comparisons with Ground-Based GPS Measurements, J. Climate, 21, 2218-2238, 2008.

Wang, P., Stammes, P., van der A, R., Pinardi, G., and van Roozendael, M.: FRESCO+: an improved $\mathrm{O}_{2}$ A-band cloud retrieval algorithm for tropospheric trace gas retrievals, Atmos. Chem. Phys., 8, 6565-6576, doi:10.5194/acp-8-6565-2008, 2008. 